\title{
Cancer morbidity among workers in the telecommunications industry
}

\author{
D VÅGERÖ, ${ }^{1}$ A AHLBOM,${ }^{2}$ R OLIN, ${ }^{3}$ AND S SAHLSTEN ${ }^{4}$ \\ From the Department of Social Medicine, ${ }^{1}$ Karolinska Institute, Huddinge University Hospital, Huddinge, \\ Department of Epidemiology, ${ }^{2}$ National Institute of Environmental Medicine, Stockholm, Preventive \\ Occupational Medicine Unit, ${ }^{3}$ Royal Institute of Technology, Stockholm, and Unit for Occupational \\ Medicine,${ }^{4}$ Teli, Nynäshamn, Sweden
}

ABSTRACT A retrospective cohort study of 2918 workers in the telecommunications industry in Sweden recorded the cancer morbidity for the period 1958-79. Cases of cancer were collected from the Swedish Cancer Registry for this period and information on work characteristics was collected for the entire period of employment. The total cancer morbidity was as expected. There was no excess risk of lung cancer but an excess risk of malignant melanoma of the skin was detected (SMR $=2 \cdot 6,12$ cases). This excess risk was particularly associated with work environments where soldering was practised. Estimates of the SMR became larger with the assumption of a longer induction/latency period.

The electrical and electronics manufacturing industry has been rapidly changing for decades, transforming the work environment in many ways and this process will probably continue in the foreseeable future. Although the production demands exceptionally good hygiene, it would be unwise to assume that there are no occupational hazards since the work frequently entails exposure to various metals, metal compounds, and organic compounds.

This was the background to an earlier study in which data from the Swedish Cancer Environment Registry were used to calculate cancer risks for this industry. This first study indicated that there might be some risk for pharyngeal and respiratory cancer in the electronics industry as a whole. ${ }^{1}$ In another study we have been following up the mortality of electrical engineers. Their general and cancer mortality was low, but three cases of melanoma were observed whereas 0.9 were expected. ${ }^{2}$

A case-control study of American women with oral and pharyngeal cancer has suggested that work in the electronics industry might be a risk factor for these cancers. ${ }^{3}$ Nevertheless, we have found no report on malignant melanoma of the skin being linked to the electronics or electrical manufacturing industry, although there is such a report for malignant melanoma of the eye. ${ }^{4}$

Received 30 April 1984

Accepted 14 May 1984
The present study has focused on one part of the electronics and electrical manufacturing industry by investigating cancer mortality and morbidity for the period 1958-79 in a large Swedish telecommunications company. The company was established in the $1910 \mathrm{~s}$ and has been pursuing research, development, and manufacturing of telecommunications equipment since then.

\section{Subjects and methods}

Three work sites belonging to the same company and with a similar product (telecommunications equipment) were studied. All the workers employed at these sites for at least six months during the period 1956-60 were entered into the study. The cohort so chosen consisted of 2918 subjects (2051 men, 867 women) and for the study period $1958-79$ the number of person-years at risk was 62028 . Work site A was established several decades before the other two and had an older work force. Forty three per cent of the cohort belonged to this site whereas the other two had $25 \%$ and $32 \%$ respectively. Sites $\mathrm{A}$ and $\mathrm{B}$ at latitudes $59^{\circ}$ and $62^{\circ}$ were both on the coast but site $\mathrm{C}$ at latitude $58^{\circ}$ was on a big inland lake.

The definition of the study cohort was based on the employee registry maintained by the management of the three work sites. For each person the files of the company were examined for information 
on the work history of the entire employment period of that person, including the period before 1956 if appropriate. The work history of an individual thus consists of information on the departments in which he has worked, specified for year and month. A group of senior engineers developed a key which specifies the sort of work done in each department. In this way subcohorts could be formed by all those ever employed in departments where a certain work practice was carried out. Thus 1517 were employed at a department where soldering was present, and 30940 person-years were at risk in this subcohort. Subcohorts were also formed of departments where, for example, oil mist, trichlorethylene, or grinding, polishing, and degreasing were present. Here, the number of person-years at risk were 1787, 7202, and 5366, respectively.

An attempt was made to describe in detail the actual work history for some of the cases of cancer, but it was difficult to ascertain actual work exposures, especially since first employment for several of these cases goes back several decades.

The unique ten digit personal identification number of each person was established through the employee registries, the local parishes, or other population registries. It was thus eventually possible to trace and identify 2916 of the 2918 . Any deaths during the study period were established through the cause of death registry. For two the status of dead or alive at the end of the study period could not be certified. Thus calculations of the number of person-years at risk were based on 2914 of the original 2918. Five who had emigrated were followed up until the year of emigration. The study population was linked to the Swedish Cancer Registry for the period 1958-79. The total number of cancer cases was 139 (102 men, 37 women).

The expected numbers were calculated from the age, sex, and calendar year specific incidence rates of the total Swedish population. These rates were multiplied by the number of person-years at risk for each stratum and the products then summarised over strata. The standardised morbidity ratio (SMR) was calculated as the ratio of observed to expected number of cases. Ninety five per cent confidence intervals were calculated. ${ }^{5}$ The analysis was either based on the entire cohort under study or on a particular subcohort, defined by a particular work practice as described above. In a further analysis risks were calculated on the assumption of a specified duration of induction/latency time. ${ }^{6}$ For the analysis the COHORT computer program was used.'

\section{Results}

There were 102 cases of cancer in men and 37 in women. This is close to expectation and the SMRs for all cancers for both men and women are 1.0. Table 1 shows the distribution of cancers for men and table 2 for women.

The number of lung cancers was similar to the expected number ( 10 observed, $11 \cdot 1$ expected for men and 1 observed, $0 \cdot 8$ expected for women).

Of particular interest are the 12 cases of malignant melanoma of the skin ( 8 men, 4 women), corresponding to a SMR (men and women combined) of $2.6(\mathrm{cl} \mathrm{1} \cdot 3-4 \cdot 5)$. These cases were all verified bye biopsy. The number of non-melanoma skin cancers? was four (all men), giving a SMR (men and women combined) of $1 \cdot 4(\mathrm{cl} 0 \cdot 4-3 \cdot 7)$. Eleven of the 12 cases of melanoma were situated on parts of the body usually covered (ICD:7 diagnosed 190.5-190.7), which is a greater proportion than could be expected. The remaining lesion was on the ear (table $3)$. There was no consistent trend of increased risk

Table 1 Observed and expected number of cancer cases among 2047 male workers 1958-79. All sites with two or more cases

\begin{tabular}{|c|c|c|c|c|}
\hline Site (ICD-7) & Obs & $\operatorname{Exp}$ & $S M R$ & $95 \%$ Confidence interval \\
\hline $\begin{array}{l}\text { Mouth (144) } \\
\text { Stomach (151) } \\
\text { Colon (153) } \\
\text { Pancreas (157) } \\
\text { Larynx (161) } \\
\text { Lung (162) } \\
\text { Prostate (177) } \\
\text { Kidney (180) } \\
\text { Urinary organs (181) } \\
\text { Malignant melanoma of skin (190) } \\
\text { Skin (melanoma excl) (191) } \\
\text { Nervous system (193) } \\
\text { Connective tissue (197) } \\
\text { Non-Hodgkin lymphoma (200) } \\
\text { Brill-Symmer's (202) } \\
\text { Other }\end{array}$ & $\begin{array}{r}2 \\
5 \\
10 \\
4 \\
2 \\
10 \\
15 \\
10 \\
6 \\
8 \\
4 \\
5 \\
3 \\
4 \\
2 \\
12\end{array}$ & $\begin{array}{r}0 \cdot 4 \\
7 \cdot 8 \\
6 \cdot 9 \\
3 \cdot 7 \\
1 \cdot 4 \\
11 \cdot 1 \\
12 \cdot 8 \\
5 \cdot 2 \\
6 \cdot 4 \\
3 \cdot 2 \\
2 \cdot 5 \\
5 \cdot 1 \\
1 \cdot 0 \\
2 \cdot 9 \\
0 \cdot 1 \\
28 \cdot 8\end{array}$ & $\begin{array}{r}4 \cdot 8 \\
0 \cdot 6 \\
1 \cdot 5 \\
1 \cdot 1 \\
1.4 \\
0.9 \\
1 \cdot 2 \\
1.9 \\
0.9 \\
2 \cdot 5 \\
1.6 \\
1.0 \\
3.0 \\
1.4 \\
17 \cdot 6 \\
0.4\end{array}$ & 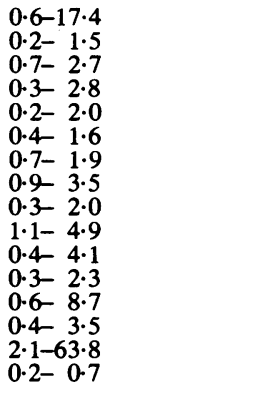 \\
\hline All cancer & 102 & $99 \cdot 3$ & 1.03 & $0.8-1.2$ \\
\hline
\end{tabular}


Table 2 Observed and expected number of cancer cases among 867 female workers 1958-79. All sites with two or more cases

\begin{tabular}{|c|c|c|c|c|}
\hline Site (ICD-7) & Obs & $\operatorname{Exp}$ & $S M R$ & $95 \%$ Confidence interval \\
\hline $\begin{array}{l}\text { Small intestine (152) } \\
\text { Breast (170) } \\
\text { Cervix uteri }(171) \\
\text { Corpus uteri }(172) \\
\text { Malignant melanoma of skin (190) } \\
\text { Other }\end{array}$ & $\begin{array}{r}2 \\
7 \\
4 \\
5 \\
4 \\
15\end{array}$ & $\begin{array}{r}0 \cdot 1 \\
10 \cdot 9 \\
4 \cdot 1 \\
2 \cdot 3 \\
1 \cdot 4 \\
18 \cdot 9\end{array}$ & $\begin{array}{r}16 \cdot 0 \\
0 \cdot 6 \\
1 \cdot 0 \\
2 \cdot 2 \\
2 \cdot 8 \\
0 \cdot 8\end{array}$ & $\begin{array}{l}1 \cdot 8-57 \cdot 8 \\
0 \cdot 3-1 \cdot 3 \\
0 \cdot 3-2 \cdot 5 \\
0 \cdot 7-5 \cdot 1 \\
0 \cdot 8-7 \cdot 2 \\
0 \cdot 4-1 \cdot 3\end{array}$ \\
\hline All cancer & 37 & $37 \cdot 7$ & 0.98 & $0.7-1.44$ \\
\hline
\end{tabular}

of melanoma with duration of employment.

On analysing the risk of melanoma for different subcohorts, the risk estimate was found to be higher for departments associated with soldering work. Table 4 shows the risk estimates, assuming at least three years of exposure and a 10 year induction/ latency period for any work and soldering work, respectively. For work in soldering departments there is a near fourfold risk. Cases in this group were clustered at one geographical location, site A. Assuming a longer induction period, the SMRs for soldering became larger, reflecting the fact that a large proportion of the cases of melanoma occurred in people who began to work in the soldering departments decades ago.

No other cancer site could be shown to be linked to a particular work practice. Nevertheless, there were two cases of Brill Symmer's disease among men compared with 0.1 expected. The ten cases of cancer of the kidney in men (all localised in the renal parenchyma) should be noted, although they do not represent a significant excess risk.

Table 3 Cases of malignant melanoma among 2914 workers during 1958-79

\begin{tabular}{llll}
\hline Year of diagnosis & Sex & Age at diagnosis & Anatomical site \\
\hline 1961 & F & 41 & Leg \\
1964 & M & 56 & Trunk \\
1967 & M & 59 & Trunk \\
1969 & M & 65 & Leg \\
1972 & F & 54 & Ear \\
1973 & M & 67 & Leg \\
1976 & M & 62 & Leg \\
1976 & M & 55 & Trunk \\
1977 & M & 34 & Trunk \\
1978 & M & 35 & Leg \\
1978 & F & 37 & Arm \\
1979 & F & 43 & Leg \\
\hline
\end{tabular}

\section{Discussion}

The total cancer morbidity in this group of workers is similar to that expected and it may be concluded that there is no general increase in the risk of cancer in this part of the electronics and electrical manufacturing industry. Neither have we found any support for an excess risk of cancer of the lung.

There were no cases of cancer of the pharynx (but one nasopharyngeal cancer) in this study, and we are thus unable to support the hypothesis that there is an excess of this tumour in the electronics industry in general. We conclude that the present study is too small or the follow up period too short either to detect or exclude such a risk. This is also true for other rate cancers of potential interest such as nasal, nasopharyngeal, and oral cancers.

There was a $2 \cdot 6$-fold increase in the number of malignant melanoma cases in this study. Those work departments where soldering was practised were associated with a near fourfold risk, assuming 10 years of latency and three years of exposure. This was an unexpected finding and we have seen no other report on the risks of malignant melanoma of the skin in this branch of industry before. We have, however, recently completed a study in which a number of melanomas greater than expected was found among electrical engineers. ${ }^{2}$

Soldering work may result in exposure to lead as well as to colophony, the main constituent of soldering flux. When soldering flux is heated, exposure to formaldehyde, abietic acid, and neoabietic acid may result. None of these is suggested as being associated with malignant melanoma, although neoabietic acid is known to be mutagenic. ${ }^{8}$

Other work practices and exposures in soldering

Table 4 Malignant melanoma among all workers and workers in soldering departments, assuming ten years' induction and at least three years' exposure

\begin{tabular}{|c|c|c|c|c|c|c|c|c|}
\hline & \multicolumn{2}{|l|}{ Men } & \multicolumn{2}{|c|}{ Women } & \multicolumn{2}{|l|}{ All } & \multirow[t]{2}{*}{$S M R$} & \multirow{2}{*}{$\begin{array}{l}95 \% \\
\text { Confidence } \\
\text { interval }\end{array}$} \\
\hline & Obs & $\operatorname{Exp}$ & Obs & $\operatorname{Exp}$ & Obs & $\operatorname{Exp}$ & & \\
\hline $\begin{array}{l}\text { Any work } \\
\text { Soldering }\end{array}$ & $\begin{array}{l}7 \\
4\end{array}$ & $\begin{array}{l}2.67 \\
0.91\end{array}$ & $\begin{array}{l}3 \\
2\end{array}$ & $\begin{array}{l}0.97 \\
0.62\end{array}$ & $\begin{array}{r}10 \\
6\end{array}$ & $\begin{array}{l}3.63 \\
1.53\end{array}$ & $\begin{array}{l}2 \cdot 8 \\
3 \cdot 9\end{array}$ & $\begin{array}{l}1 \cdot 3-5 \cdot 1 \\
1 \cdot 4-8 \cdot 5\end{array}$ \\
\hline
\end{tabular}


departments should be considered, since they might be confounding variables in the analysis. Such potential confounders were looked for and discussed with representatives of the management and the workers. Since a large number of items in the finished electronic assemblies were coated with material containing nickel, exposure to nickel was especially frequent. Nickel has not been linked with malignant melanoma of the skin in man. Exposure to ebonite and plastic insulation materials was also common.

There are few studies in which evidence for occupational risk factors in the aetiology of malignant melanoma has been sought. ${ }^{y-11}$ In one a threefold risk for laboratory personnel was reported and chemists were singled out as being especially at risk. ${ }^{9}$ A further study was unable to confirm any of the results from the first, however. ${ }^{10}$ There is a clear social class gradient in the risk of malignant melanoma in Sweden and blue collar workers have been found to have a SMR of $0 \cdot 86 .^{12}$ This should be noted, since it implies that our comparison of telecommunications industry workers with the general population, rather than with the population of blue collar workers, would tend to give too low an estimate of risk.

Solar radiation is generally understood to be the predominant risk factor for malignant melanoma, ${ }^{1314}$ although it has also been suggested that it might play a minor part. ${ }^{15}$ The number of severe sunburns are probably more important than the life time dose of radiation. ${ }^{1617}$

Since two of the work sites were on the coast the possibility of a greater exposure to the sun could not be rule out and should therefore be considered. It seems unlikely, however, that the subcohort with increased risk should have a different pattern of sun exposure than that of the rest of the group. The clustering of cases of melanoma was at site A. To exclude geographical location as a confounder, the number of cases in all other branches of industry at this geographical location was calculated from the Swedish Cancer Environment Registry. No significant excess risk was found ( $\mathrm{H}$ Kiviranta, unpublished data).

The evidence for sun exposure as a cause of malignant melanoma is strongest for those sites of the body that are uncovered, but 11 of the 12 melanomas in our study were on the covered parts of the body. ${ }^{18}$ Moreover, non-melanoma skin cancers which are known to be linked to sun exposure were not significantly raised in the group.

Thus solar radiation is not likely to be the risk factor we are looking for, but it might possibly interact with that factor. Trying to disentangle the effects of occupational risk factors, potential con- founders, and chance, we have therefore concluded that the most likely risk factor is of occupational origin.

It has been suggested that exposure of indoor workers to fluorescent lighting is a risk factor for malignant melanoma. ${ }^{19}$ The extent of this exposure in the cohort studied is not known, and we could not exclude this as a potential confounder, although we are aware of no reason why the studied cohort would have an exposure to fluorescent lighting different from that of the general population.

The induction/latency for malignant melanoma has earlier been suggested to be short, perhaps only two to five years.9 It is possible, however, that although the induction time for solar radiation is short, some other factor acting earlier in the causal sequence may have a much longer induction period. There is some evidence that exposure to chemical agents preceeding ultraviolet radiation or solar radiation increases the risk and, if so, may be a cause with a longer induction/latency period. ${ }^{20}$

Of other cancers, the two cases of the extremely rare Brill-Symmer's disease should be noted. They occurred at different geographical locations, were widely separated in time, and had no obvious association with work. It is also difficult to say if they really represent the same disease entity.

Although the ten cases of cancer of the kidney in 8 men do not represent a significantly raised risk, they should also be noted. Cancer of the kidney has, however, rarely been linked to occupational hazards ? and could not be linked in this study to any particular work environment.

Some final problems pertinent to the interpretation of the results should be mentioned. The forming of subcohorts is based on information about the department to which the person belonged, rather than the work he was actually doing. This leaves us with a rather inprecise instrument for finding occupational risk factors and some caution is therefore advisable. For instance, it has not been possible to include into a few well defined exposure categories those environmental factors present in soldering departments during the past three, four, or even five decades. This is, however, more likely to lead to failure to detect a real occupational risk than the reverse. Any excess risk would also tend to be underestimated since misclassifications would be non-differential. The case finding is based on the cancer registry both in the exposed cohort and in the reference population, and there should, therefore, be no risk of observation bias.

Despite the fact that chance appears unlikely to explain the present results on risk of melanoma, and we can find no obvious bias that could account for the association, the finding must be considered ten- 
tative, inasmuch as it has not been reported previously.

Requests for reprints to: Denny Vågerö, Department of Social Medicine, Huddinge University Hospital B 44, S-141 86 Huddinge, Sweden.

\section{References}

' Vågerö D, Olin R. Incidence of cancer in the electronics industry; using the new Swedish Cancer Environment Registry as a screening instrument. Br J Ind Med 1983;40:188-92.

2 Olin R, Vågerö D, Ahlbom A. Mortality experience of electrical engineers. Br.J Ind Med (in press).

${ }^{3}$ Wim D, Blot W, Shy C, Fraumeri J. Occupation and oral cancer among women in the South. Am J Ind Med 1982;3:161-7.

4 Swerdlow AJ. Epidemiology of eye cancer in adults in England and Wales, 1962-77. Am J Epidemiol 1983;118:294-300.

${ }^{5}$ Rothman K, Boice I. Epidemiologica analysis with a programmable calculator. Boston; Epidemiology Resources Inc, 1982.

- Rothman K. Induction and latent periods. Am J Epidemiol 1981;114:253-9.

7 Anjou C-G, Andersson K, Axelson O, Edling C-H, Samuelsson P-G, Wigertz O. A computer system for occupational health epidemiology. In: Lindberg D, Reichertz P, eds. Proceedings from the Conference in Medical Informatics in Toulouse 1981. Berlin: Springer Verlas, 1981.

${ }^{8}$ Lee E, Nestmann E, Müller J, Douglas GR. Mutagenicity of compounds identified in pulp and paper mill effluents using the Salmonella-mammalian-microsome assay. Genetics 1979;91 (4 part, 2 suppl): 66.

' Austin DF, Reynolds PJ, Snyder MA, Biggs MW, Stubbs HA.
Malignant melanoma among employees of the Lawrence Livermore National Laboratory. Lancet 1981;ii:712-6.

${ }^{10}$ Acquavella JF, Tietjen GL, Wilkinson GS, Key CR, Voelz GL. Malignant melanoma incidence at the Los Alamos National Laboratory. Lancet 1982; i: $883-4$.

" Bahn AK, Rosenwaike I, Hermann N, Grover P, Stellman J, O'Leary K. Melanoma after exposure to PBCs. N Engl J Med 1976;295:450.

12 Vågerö D, Persson G. Risks, survival and trends of malignant melanoma among white and blue collar workers in Sweden. Soc Sci Med 1984:19:475-8.

${ }^{13}$ Lee J. Melanoma and exposure to sunlight. Epidemiologic Reviews 1982;4:110-36.

14 Magnus K. Incidence of malignant melanoma of the skin in the five Nordic countries. Significance of solar radiation. Int $J$ Cancer 1977; 20:447-85.

is Anonymous. The aetiology of melanoma [Editorial]. Lancet 1981;i:253-6.

${ }^{16}$ MacKie RM, Aitchinson TC. Severe sunburn and subsequent risk of primary cutaneous malignant melanoma in Scotland. $\mathrm{Br}$ $J$ Cancer 1982;446:955-60.

${ }^{17}$ Elwood JM, Gallagher RP, Hill GB, Spinelli JJ, Pearson JCG, Threlfall $W$. Pigmentation and skin reaction to sun as risk factors for cutaneous melanoma. Br Med J 1984;288:99-102.

${ }^{18}$ Armstrong B, Heenan P. A theory of the etiology and pathogenesis of human cutaneous malignant melanoma. Journal of the National Cancer Institute 1983;4:651-6.

${ }^{14}$ Beral V, Evans S, Shore H, Milton G. Malignant melanoma and exposure to fluorescent lighting at work. Lancet 1982;ii:2903.

${ }^{20}$ Davies R. Interaction of light and chemicals in carcinogenesis. International conference on ultraviolet carcinogenesis. Bethesda: National Cancer Institute, 1978. (National Cancer Institute monograph No 50.) 